\title{
Erratum to: Apigenin induces apoptosis via extrinsic pathway, inducing p53 and inhibiting STAT3 and NFkB signaling in HER2-overexpressing breast cancer cells
}

\author{
Hye-Sook Seo $\cdot$ Han-Seok Choi - Soon-Re Kim • Youn Kyung Choi \\ Sang-Mi Woo • Incheol Shin · Jong-Kyu Woo • Sang-Yoon Park • \\ Yong Cheol Shin $\cdot$ Seong-Gyu Ko
}

Published online: 15 June 2012

(C) Springer Science+Business Media, LLC. 2012

\section{Erratum to: Mol Cell Biochem}

DOI 10.1007/s11010-012-1310-2

In the original article the name of Seong-Kyu Ko is misspelled. The correct spelling of the corresponding author's name is Seong-Gyu Ko.

Everything else in the article remains correct.

The online version of the original article can be found under doi: 10.1007/s11010-012-1310-2.

H.-S. Seo - H.-S. Choi - S.-R. Kim - Y. K. Choi - S.-M. Woo ·

Y. C. Shin · S.-G. Ko $(\bowtie)$

Laboratory of Clinical Biology and Pharmacogenomics and Center for Clinical Research and Genomics, Institute of Oriental Medicine, Kyung Hee University, 1 Hoegi-dong, Dongdaemun-gu, Seoul 130-701, Republic of Korea

e-mail: epiko@khu.ac.kr

I. Shin

Department of Life Science, College of Natural Sciences,

Hanyang University, Seoul 133-791, Republic of Korea

J.-K. Woo

Department of Pathology, Tumor Immunity Medical Research Center, Cancer Research Institute, College of Medicine, Seoul

National University, Seoul 110-799, Republic of Korea

S.-Y. Park

Cancer Preventive Material Development Research Center,

College of Oriental Medicine, Kyung Hee University,

Seoul 130-701, Republic of Korea 